\title{
NOVEL HETEROCYCLES BASED ON 1, 3, 4- THIADIAZOLE SCAFFOLD AS INSECTICIDES
}

Madkour, H. F. ${ }^{(1)}$; Azab, M. E. ${ }^{(1)}$; Aly, A. F. ${ }^{(2)}$ and Khamees, M. S. M. ${ }^{(1)}$ 1) Synthetic Organic Chemistry Lab, Chemistry Department, Faculty of Science, Ain Shams University. 2) Central Agricultural Pesticide Lab., Pesticide Formulations Department, Agricultural Research Center, Dokky, Giza, Egypt.

\begin{abstract}
The crop plants are the major source of human nutrition, but insects and pests cause huge economic losses every year. The authors were interested in developing novel insecticidal agents with low toxicity and an acceptable impact on the environment. Thus, 2-amino-5-(substituted)-1, 3, 4-thiadiazoles $(1 \mathrm{a}, \mathrm{b})$ were used as versatile materials to synthesize novel compounds through reaction with different electrophiles. The insecticidal activity of the synthesized compounds was tested using 4th instar larvae of spodoptera littoralis. Most of the tested compounds showed good to excellent insecticidal activity. Thus, the synthesized compounds could be used in the field of pest control through using them in proper pesticide formulations.
\end{abstract}

Keywords: Insecticidal activity, 1, 3, 4-Thiadiazole, Thiadiazolopyrimidine, Imidazothiadiazole, Spodoptera littoralis.

\section{INTRODUCTION}

It is well established that 1,3,4-thiadiazoles and their derivatives exhibit a broad spectrum of biological activities not only in research on drugs as anticancer (Flefel et al. 2017), antimicrobial (Rezki et al. 2015], antituberculosis (Patel, et al. 2017) anticonvulsant (Rahman et al. 2014), antiviral (Yu et al. 2017) or anti-inflammatory activities (Maddila et al. 2016) but also in pesticide research such as antifungal (Zhang et al. 2014), insecticidal (MO et al. 2015, Li et al. 2014, Qian et al. 2013) herbicidal 
(Kalhor and Dadras 2013) and also plant growth regulating agents (Chen et al. 2007).

The crop plants are the major source of human nutrition, but the crop losses due to insects cause huge economic losses every year. The chemical pesticides are still the major approach available for their control, but their application is associated with development of insecticide resistance along with the environmental concerns and health hazards in human and animals. This has continuously prompted for the development of durable and cost effective alternative pest control strategies.

Consequently, studies on the synthesis and bioassays of 1,3,4-thiadiazole derivatives have attracted increasing attention in the field of pesticide discovery. As pesticides, many of the 1,3,4- thiadiazole derivatives showed high toxicity profiles and were taken off the market.

For the above mentioned reasons and in continuation of our program in the synthesis of biologically active heterocyclic compounds (Madkour et al. 2014, Azab, et al. 2015, 2016), the authors were interested in developing novel environmentally friendly insecticidal agents with low toxicity.

Thus, the authors utilized 2-amino-5-(2-chlorophenyl)-1, 3, 4-thiadiazole (1a) and 2-amino-5-(4-iodophenyl)-1,3,4-thiadiazole (1b) as versatile materials to synthesize novel compounds though reaction with different electrophiles. The structures of the newly synthesized compounds were elucidated using the IR, 1HNMR, mass spectroscopy and elemental analyses. Also, the insecticidal activity of the synthesized compounds was tested using 4th instar larvae of spodoptera littoralis. Most of the tested compounds 
showed good to excellent insecticidal activity.

\section{MATERIALS AND METHODS}

1- Chemistry: All melting points are uncorrected and were determined on a Gallen Kamp electric melting point apparatus. The microanalyses were within $\pm 0.4 \%$ of theoretical values and were carried out at the Microanalytical Centre, National Research Centre, Cairo, Egypt. IR spectra (in $\mathrm{KBr}$ ) were recorded on Shimadzu FT-IR 8101 PC using the OMNIC program and are reported as frequency of absorption in $\mathrm{cm}-1$. 1H-NMR spectra were recorded on a Bruker spectrophotometer at 400 $\mathrm{MHz}$ using tetramethylsilane (TMS) as internal standard. 13C-NMR spectra were recorded on the same spectrometer at $100 \mathrm{MHz}$. Electron Ionization (EI)-MS were measured on a Shimadzu- GC-MS-QP-1000 EX mass spectrometer instrument operating at $70 \mathrm{eV}$. The purity of the new synthesized compounds was checked by $0.2 \mathrm{~mm}$ layer thickness Fluka aluminum-backed TLC plates with detection by UV quenching at $254 \mathrm{~nm}$. The starting thiadiazoles $1 \mathrm{a}, \mathrm{b}$ were prepared according to Mullick et al. method (2011).

5-(2-Chlorophenyl)-1,3,4-thiadiazol-2-amine (1a): $\quad$ mp 198-200 oC (literature 204-206 oC); Color: Reddish brown; Solvent (EtOH), Yield: 81\%; MS: m/z 211 [M+·] (1.87\%). Anal. Calcd for C8H6N3ClS (211): C, 45.49; H, 2.84; N, 19.90; Cl, 16.82; S, 15.16. Found: C, 45.85; H, 3.13; N, 20.20; Cl, $16.49 ; \mathrm{S}, 15.55$.

5-(4-Iodophenyl)-1,3,4-thiadiazol-2-amine (1b): mp 230-232 oC; Color: Brown; Solvent (EtOH); Yield: 74\%; IR cm-1: 3287, 3103 (NH2), 1631 $(\mathrm{C}=\mathrm{N}), 1592(\mathrm{C}=\mathrm{C})$; 1HNMR (DMSO-d6) $\square$ 7.43-7.99 (m, 4H, Ar-H), 8.10 
(s, 2H, NH2, D2O exchangeable); MS: m/z 303 [M+·] (4.83\%). Anal. Calcd for C8H6N3IS (303): C, 31.68; H, 1.98; N, 13.86; I, 41.91; S, 10.56. Found: C, 32.00; H, 2.19; N, 14.21; I, 42.29; S, 10.20.

\section{1-(4-Chlorophenyl)-N-(5-(2-chlorophenyl)-1,3,4-thiadiazol-2-yl)-methan-} imine (2).

A mixture of compound 1a $(0.01 \mathrm{~mol}, 2.11 \mathrm{~g})$ and p-chloro-benzaldehyde $(0.01 \mathrm{~mol}, 1,41 \mathrm{~g})$ was fused at $150 \mathrm{oC}$ for $4 \mathrm{~h}$. The mixture was left to cool at room temperature and the solid product was collected, and recrystallized to give 2 .

mp 246-248 oC; Color: brown; Solvent (EtOH), Yield: 60\%; IR cm-1: 3064, (CHar), $1640(\mathrm{C}=\mathrm{N}), 1591$ (C=C); 1HNMR (DMSO-d6) $\square$ 7.42-8.20 (m, 8H, Ar-H), 9.15 (s, 1H, CH=N); MS: m/z 333 [M+· (3.83\%). Anal. Calcd for C15H9N3Cl2S (333): C, 54.05; H, 2.70; N, 12.61; Cl, 21.02; S, 9. 61. Found: C, 53.75; H, 2.53; N, 12.30; Cl, 20.69; S, 10.00.

\section{2-(2-Chlorophenyl)-5-(4-chlorophenyl)-7-hydroxy-5H-[1,3,4]thiadiazolo-}

\section{[3,2-a]pyrimidine-6-carbonitrile (4).}

A mixture of $1 \mathrm{a}(0.01 \mathrm{~mol}, 2.11 \mathrm{~g})$ and arylidene cyanoacetate $3(0.01$ mol, $2.33 \mathrm{~g})$ in ethanol $(20 \mathrm{~mL})$ was refluxed for $3 \mathrm{~h}$ in the presence of $1 \mathrm{ml}$ of piperidine as a catalyst. The reaction mixture was poured onto ice-cold water, acidified with dilute $\mathrm{HCl}$, the precipitated solid was filtered off, dried and recrystallized to give 4 .

m.p. 170-172 oC; Color: pale yellow; Solvent (Benzene), Yield: 65\%; IR cm-1: 3337 (OH), 3056, (CHar), 2213 (CN); 1HNMR (DMSO-d6) $\square 3.82$ (s, 1H, benzylic-H), 6.94-8.18 (m, 8H, Ar-H), $10.43(\mathrm{~s}, 1 \mathrm{H}, \mathrm{OH}, \mathrm{D} 2 \mathrm{O}$ 
exchangeable); MS: m/z 400 [M+· $\quad$ (4.40\%). Anal. Calcd for C18H10N4Cl2OS (400): C, 54.00; H, 2.50; N, 14.00; Cl, 17.50; S, 8. 00. Found: C, 53.69; H, 2.68; N, 13.70; Cl, 17.88; S, 8.39.

\section{7-Amino-2-(2-chlorophenyl)-5-(4-chlorophenyl)-5H-[1,3,4]thiadiazolo}

\section{[3,2-a]pyrimidine-6-carbonitrile (8).}

A mixture of $1 \mathrm{a}(0.01 \mathrm{~mol}, 2.11 \mathrm{~g})$ and arylidene malononitrile $7(0.01$ $\mathrm{M}, 2.04 \mathrm{~g})$ in ethanol $(20 \mathrm{~mL})$ was refluxed for $3 \mathrm{hr}$. in the presence of $1 \mathrm{ml}$ of piperidine as a catalyst. The reaction mixture was poured onto ice-cold water, acidified with dilute $\mathrm{HCl}$, the precipitated solid was filtered off, washed with water, dried and recrystallized to give 8 .

m.p. 160-162 oC; Color: brown; Solvent (EtOH), Yield: 53\%; IR cm-1: 3339, 3235 (NH2), 2211 (CN); 1HNMR (DMSO-d6) $\square 3.75$ (s, 1H, benzylic$\mathrm{H})$, 6.80-7.84 (m, 8H, Ar-H), 9.03 (s, 2H, NH2, D2O exchangeable); MS: m/z 399 [M+· (3.12\%). Anal. Calcd for C18H11N5Cl2S (399): C, 54.13; H, 2.76; N, 17.54; Cl, 17.54; S, 8. 02. Found: C, 53.88; H, 3.00; N, 17.87; Cl, 17.90; S, 8.40.

\section{6-Acetyl-2-(2-chlorophenyl)-5-(4-chlorophenyl)-8,8a-dihydro-7H-[1,3,4]-}

\section{thiadiazolo[3,2-a]pyrimidin-7-one (9)}

A mixture of 1a (0.005 mol, $1.05 \mathrm{~g})$, p-chlorobenzaldehyde (0.005 mol, $0.705 \mathrm{~g})$ and ethyl acetoacetate $(0.005 \mathrm{~mol}, 0.65 \mathrm{~mL})$ was heated at $60^{\circ} \mathrm{C}$ under solvent-free conditions for $5 \mathrm{~h}$. The reaction mixture was allowed to cool, then the product was collected, washed 3 times $(3 \times 20 \mathrm{ml})$ with water and diethyl ether, dried and recrystallized to produce 9 .

m.p. 178-180 oC; Color: yellowish brown; Solvent (Benzene), Yield: 59\%; IR cm-1: 3159 (NH), 1698 and 1649 (C=O); 1HNMR (DMSO-d6) 
2.23 (s, 3H, CH3), 7.36 (s,1H, S-CH-N), 7.49-8.11 (m, 8H, Ar-H), 12.67 (s, 1H, NH, D2O exchangeable); MS: m/z 399 [M+· (3.12\%). Anal. Calcd for C19H13N3Cl2O2S (417): C, 54.67; H, 3.12; N, 10.07; Cl, 16.78; S, 7.67. Found: C, 55.00; H, 3.31; N, 9.78; Cl, 17.07; S, 7.29.

\section{5-Amino-2-(2-chlorophenyl)-7H-[1,3,4]thiadiazolo[3,2-a]pyrimidin-7-one} $\underline{(10)}$

A solution of sodium $(0.23 \mathrm{~g})$ in dry methanol $(15 \mathrm{ml})$ was prepared and added to a mixture of $1 \mathrm{a}(0.005 \mathrm{~mol}, 1.05 \mathrm{~g})$ and ethyl cyanoacetate $(0.005$ mol, $0.57 \mathrm{~mL}$ ), and refluxed for $8 \mathrm{~h}$. The reaction mixture was left to cool at room temperature and poured onto ice-cold water, acidified with dilute $\mathrm{HCl}$. The precipitated solid was filtered off, dried and recrystallized to furnish 10 .

m.p. 202-204 oC; Color: pale yellow; Solvent (EtOH), Yield: 58\%; IR cm-1: 3287, 3102 (NH2), 1693 (C=O); 1HNMR (DMSO-d6) $\square 7.42$ (s,2H, NH2, D2O exchangeable), 7.49-8.11 (m, 8H, Ar-H), 12.67 (s, 1H, NH, D2O exchangeable); MS: m/z 278 [M+· $\quad$ (80.09\%). Anal. Calcd for C11H7N4ClOS (278): C, 47.48; H, 2.52; N, 20.14; Cl, 12.59; S, 11.51. Found: C, 47.10; H, 2.79; N, 19.81; Cl, 12.92; S, 11.84 .

\section{2-(2-Chlorophenyl)-6-0x0-5,6-dihydroimidazo[2,1-b][1,3,4]thiadiazole-5- carbonitrile (12).}

A mixture of $1 \mathrm{a}(0.01 \mathrm{~mol}, 2.11 \mathrm{~g})$ and ethyl cyanoacetate $(0.01 \mathrm{~mol}$, $1.13 \mathrm{~mL}$ ) was fused for $3 \mathrm{~h}$, then left to cool at room temperature. The solid residue was collected, and recrystallized to produce 12 .

m.p. 226-228 oC; Color: brown; Solvent (Butanol), Yield: 65\%; IR cm-1: $2261(\mathrm{CN}), 1701(\mathrm{C}=\mathrm{O})$; 1HNMR (DMSO-d6) $\square 7.42$ (s,2H, NH2, D2O 
exchangeable), 6.96-7.93 (m, 4H, Ar-H), 8.38 (s, 1H, N-CH-CN); MS: m/z 276 [M+· (1.15\%). Anal. Calcd for C11H5N4ClOS (276): C, 47.82; H, 1.81; N, 20.29; Cl, 12.68; S, 11.59. Found: C, 48.16; H, 2.02; N, 19.98; Cl, 13.00; S, 11.20.

\section{2-(2-Chlorophenyl)-5H-[1,3,4]thiadiazolo[3,2-a]pyrimidine-5,7(6H)-dione} (13).

1- Solvent-free conditions: A mixture of $\mathbf{1 a}(0.005 \mathrm{~mol}, 1.05 \mathrm{~g})$, and diethyl malonate $(0.005 \mathrm{~mol}, 0.80 \mathrm{~mL})$ was heated at $60^{\circ} \mathrm{C}$ under solvent-free conditions for $5 \mathrm{~h}$. The reaction mixture was allowed to cool, then the product was collected, washed 3 times $(3 \times 20 \mathrm{ml})$ with water and diethyl ether, dried and recrystallized to furnish 13.

2- Reflux conditions: A mixture of 1a (0.005 mol, $1.05 \mathrm{~g})$, and diethyl malonate $(0.005 \mathrm{~mol}, 0.80 \mathrm{~mL})$ was refluxed in $20 \mathrm{~mL}$ acetic acid for $8 \mathrm{~h}$. The reaction mixture was allowed to cool, the excess solvent was removed in vacuum and solid obtained was collected, washed with water and recrystallized.

m.p. $248-250{ }^{\circ} \mathrm{C}$; Color: pale yellow; Solvent (Butanol), Yield: 62\%; IR

$\mathrm{cm}^{-1}$ : 3022 (CH ar), 2990 (CHaliph), 1701 and 1683 (two $\mathrm{C}=\mathrm{O}$ ); ${ }^{1} \mathrm{HNMR}$ $\left(\mathrm{DMSO}-d_{6}\right) \delta 2.20\left(\mathrm{~s}, 2 \mathrm{H}, \mathrm{CO}-\mathrm{CH}_{2}-\mathrm{CO}\right), 7.47-8.03(\mathrm{~m}, 4 \mathrm{H}, \mathrm{Ar}-\mathrm{H}) ; \mathrm{MS}: \mathrm{m} / \mathrm{z}$ 279 [ $\left.\mathrm{M}^{+\cdot}\right]$ (1.87\%). Anal. Calcd for $\mathrm{C}_{11} \mathrm{H}_{6} \mathrm{~N}_{3} \mathrm{ClO}_{2} \mathrm{~S}$ (279): C, 47.31; H, 2.15; N, 15.05; Cl, 12.54; S, 11.47. Found: C, 46.99; H, 2.35; N, 14.75; Cl, 12.80; S, 11.11 . 


\section{2-(2-Chlorophenyl)-N-phenyl-7,7a-dihydro-6H-[1, 3, 4]thiadiazolo[3,2-b]-}

\section{$[1,2,4]$ thiadiazol-6-imine (15).}

A mixture of $1 \mathrm{a}(0.01 \mathrm{~mol}, 2.11 \mathrm{~g})$ and phenyl isothiocyanate $(0.01 \mathrm{~mol}$, $1.35 \mathrm{~g})$ in dioxane $(20 \mathrm{~mL})$ was refluxed for $3 \mathrm{hr}$., then the mixture left to cool, poured into ice-cold water. The precipitated solid was filtered off, washed with water, dried and recrystallized to give 15 .

mp 264-266 oC; Color: white; Solvent (Dioxane), Yield: 72\%; IR cm-1: 3329, $3252(\mathrm{NH}), 1626(\mathrm{C}=\mathrm{N})$; 1HNMR (DMSO-d6) $\square 3.56$ (s,1H, N-CH-S), 7.33-8.01 (m, 4H, Ar-H), 10.52 (s, 1H, NH, D2O exchangeable); MS: m/z $346[\mathrm{M}+\cdot]$ (53.3\%). Anal. Calcd for C15H11N4ClS2 (346): C, 52.02; H, 3.18; N, 16.18; Cl, 10.12; S, 18.50. Found: C, 51.70; H, 2.99; N, 16.51; Cl, 10.48; S, 18.13 .

\section{Dimethyl (5-(2-chlorophenyl)-1,3,4-thiadiazol-2-yl)carbonimidodithioate} (16).

To a solution of 1a $(0.01 \mathrm{~mol}, 2.11 \mathrm{~g})$ in D.M.F. $(20 \mathrm{~mL})$, a mixture of sodium hydroxide $(20 \mathrm{M})$ and carbon disulfide $(0.2 \mathrm{~mol}, 1.52 \mathrm{~mL})$ was added with stirring for $1 \mathrm{~h}$, then methyl iodide $(0.02 \mathrm{~mol}, 2.84 \mathrm{ml})$ was added dropwise within 30 min with continuous stirring. The mixture was stirred for further stirring $3 \mathrm{~h}$, and then poured onto ice- water. The precipitated solid was filtered off, dried and recrystallized to produce 16 .

m.p. 195-197 oC; Color: yellow; Solvent (Dioxane), Yield: 63\%; IR cm1: 2970, 2924 (CHaliph), 1629 (C=N); 1HNMR (DMSO-d6) $\square 4.24$ (s,6H, 2 CH3), 7.59-8.11 (m, 4H, Ar-H); MS: m/z 315 [M+·] (7.21\%). Anal. Calcd for 
C11H10N3ClS3 (315): C, 41.90; H, 3.17; N, 13.33; Cl, 11.11; S, 30.47. Found: C, 42.22; H, 2.91; N, 12.98; Cl, 11.49; S, 30.09.

\section{N-(5-(2-Chlorophenyl)-1, 3, 4-thiadiazol-2-yl)benzenesulfonamide (17).}

A mixture of 1a $(0.01 \mathrm{~mol}, 2.11 \mathrm{~g})$ and benzenesulfonyl chloride $(0.01$ mol, $1.76 \mathrm{~g})$ in dry pyridine $(15 \mathrm{~mL})$ was heated in sand bath at $150-160^{\circ} \mathrm{C}$ for $3 \mathrm{~h}$. The reaction mixture was left to cool at room temperature and poured onto ice-cold water, acidified with dilute $\mathrm{HCl}$. The precipitated solid was filtered off, dried and recrystallized to give 17.

mp 185-187 oC; Color: dark yellow; Solvent (Benzene), Yield: 50\%; IR cm-1: 3286, $3103(\mathrm{NH}), 1639(\mathrm{C}=\mathrm{N})$; 1HNMR (DMSO-d6) $\square 7.42$ (s, 1H, NH, D2O exchangeable), 7.45-8.01 (m, 4H, Ar-H); MS: m/z 351 [M+·] (21.14\%). Anal. Calcd for $\mathrm{C} 14 \mathrm{H} 10 \mathrm{~N} 3 \mathrm{ClO} 2 \mathrm{~S} 2$ (351): C, 47.86; H, 2.85; N, 11.96; Cl, 9.97; S, 18.23. Found: C, 48.15; H, 3.11; N, 12.30; Cl, 10.33; S, 17.89 .

\section{N-(5-(2-Chlorophenyl)-1, 3, 4-thiadiazol-2-yl)acetamide (18).}

A solution of $1 \mathrm{a}(0.05 \mathrm{~mol}, 1.05 \mathrm{~g})$ in acetic anhydride $(10 \mathrm{ml})$ was refluxed for $10 \mathrm{~min}$, then left to cool, and poured onto ice cold water with vigorous stirring. The separated material was collected by filtration, washed with water, dried and recrystallized to produce 18.

m.p. 246-248 oC; Color: yellow; Solvent (Dioxane), Yield: 68\%; IR cm1: 3252, $3161(\mathrm{NH}), 2914$ (CHaliph), 1699 (C=O); 1HNMR (DMSO-d6) 2.23 (s, 3H, CH3), 7.49-8.14 (m, 4H, Ar-H), 12.67 (s, 1H, NH, D2O exchangeable); MS: m/z 253 [M+.] (26.00\%). Anal. Calcd for C10H8N3ClOS (253): C, 47.43; H, 3.16; N, 16.60; Cl, 13.83; S, 12.65. Found: C, 47.08; H, 2.91; N, 16.92; Cl, 14.20; S, 13.00. 


\section{Ethyl 2-(2-chlorophenyl)-5-oxo-5H-[1, 3, 4]thiadiazolo[3,2-a]pyrimidine-}

\section{7-carboxylate (20).}

A mixture of 1a $(0.02 \mathrm{~mol}, 4.22 \mathrm{~g})$ and DADC (Diethyl acetylenedicarboxylate) $(0.02 \mathrm{~mol}, 3.4 \mathrm{~mL})$ in methanol $(20 \mathrm{~mL})$ was refluxed for $12 \mathrm{hr}$. The reaction mixture was allowed to cool, then the separated material was collected by filtration, washed with water, dried and recrystallized to furnish 20 .

m.p. 168-170 oC; Color: orange; Solvent (EtOH), Yield: 78\%; IR cm-1: 3015 (CHar), 2979 (CHaliph), 1744, 1699 (two C=O); 1HNMR (DMSO-d6)

$1.35(\mathrm{t}, 3 \mathrm{H}, \mathrm{CH} 2 \mathrm{CH} 3, \mathrm{~J}=6.9 \mathrm{~Hz}), 4.43(\mathrm{q}, 2 \mathrm{H}, \mathrm{CH} 2 \mathrm{CH} 3, \mathrm{~J}=6.9 \mathrm{~Hz}), 6.70$ (s, 1H, pyrimidine-H), 7.59-8.02 (m, 4H, Ar-H); MS: m/z 335 [M+·] (100\%). Anal. Calcd for C14H10N3ClO3S (335): C, 50.15; H, 2.99; N, 12.54; Cl, 10.45; S, 9.55. Found: C, 49.19; H, 3.27; N, 12.80; Cl, 10.09; S, 9.19.

\section{2-Chloro-N-(5-(4-iodophenyl)-1, 3, 4-thiadiazol-2-yl)acetamide (21)}

To a suspension of $1 \mathrm{~b}(0.006 \mathrm{~mol}, 1.78 \mathrm{~g})$ in dry benzene $(20 \mathrm{~mL})$ mixed with dry pyridine $(2 \mathrm{~mL})$, chloroacetyl chloride $(0.006 \mathrm{~mol}, 0.7 \mathrm{~mL})$ in dry benzene $(10 \mathrm{~mL})$ was added dropwise with stirring. The mixture was refluxed for $8 \mathrm{hr}$. The reaction mixture was cooled and the solid that separated out was collected by filtration, washed with water, dried and recrystallized to furnish 21.

m.p. 286-288 oC; Color: gray; Solvent (Dioxane), Yield: 74\%; IR cm-1: 3431, 3159 (NH), 22896 (CHaliph), 1701 (C=O); 1HNMR (DMSO-d6) $2.22(\mathrm{~s}, 2 \mathrm{H}, \mathrm{COCH} 2-\mathrm{Cl}), 4.48(\mathrm{~s}, 1 \mathrm{H}$, olefinic-H), 7.72-7.92 (m, 4H, Ar-H), $12.65(\mathrm{~s}, 1 \mathrm{H}, \mathrm{OH}, \mathrm{D} 2 \mathrm{O}$ exchangeable), 13.06 (s, 1H, NH, D2O 
exchangeable); MS: m/z 379 [M+·] (100\%). Anal. Calcd for C10H7N3CIIOS (379): C, 31.66; H, 1.85; N, 11.08; Cl, 9.23; I, 33.51; S, 8.44. Found: C, $32.00 ; \mathrm{H}, 2.11 ; \mathrm{N}, 10.78 ; \mathrm{Cl}, 8.88 ; \mathrm{I}, 33.90 ; \mathrm{S}, 8.80$.

\section{INSECTICIDAL ACTIVITY}

Susceptible strain Insect: The cotton leaf worm strain in the present study was taken from field colony and reared in central agricultural pesticide laboratory. This strain was obtained from Sharkia governorate. The strain was kept under laboratory conditions at $25 \pm 2{ }^{\circ} \mathrm{C}$ and $65 \pm 5 \%$ relative humidity away from any chemical pressure.

Chemicals used: The newly synthesized thiadiazole derivatives.

Method of bioassay technique: The effects of the synthesized thiadiazole derivatives on 4th instar larvae of S. Littoralis were determined using the leaf dipping technique to simulate the actual treatments under field conditions (Ahmed, 2009). A stock solution of each chemical was freshly prepared. Subsequent water dilution was made to achieve serial concentrations of 250, 500, 750, 1000 and 1250 ppm. Fresh castor bean leaves were dipped in each concentration for ten seconds then left to dry. The treated leaves were transferred to petri-dishes and ten larvae were placed in each one then it was covered. Leaf discs immersed in distilled water were used as control treatment. On drying, the leaf discs were placed in individual Petri dishes (9$\mathrm{cm}$ diameter). Each treatment (concentration) was replicated 3 times, including water solvent control. Ten of 4th instar larvae were placed on each leaf disc (replication), and thus the total number of tested larvae per concentration was 30 . Mortalities were recorded 24 hours after insecticides 
treatment. Mortality data were corrected using Abbott, $\mathrm{s}$ formula (Abbott, 1925) and subjected to statistical analysis by the method of Finney (1952). The LC50 and toxicity index were also estimated.

\section{RESULTS AND DISCUSSION}

Chemistry: The starting materials $1 \mathrm{a}, \mathrm{b}$ were prepared as previously reported by Mullick et al. (2011). When compound 1a was fused with pchlorobenzaldehyde for 4h, 1-(4-chlorophenyl)-N-(5-(2-chlorophenyl)-1,3,4thiadiazol-2-yl)methanimine (2) was obtained in a good yield. The structure of the Schiff base 2 was elucidated from its spectral data, where the IR spectrum devoid any bands for the NH2 group, while 1HNMR spectrum showed (s, $1 \mathrm{H})$ at $\square 9.16$ corresponding to the aza-methine proton $(\mathrm{CH}=\mathrm{N})$.

Reaction of 1a with the ethyl 3-(4-chlorophenyl)-2-cyanoacrylate (3) in refluxing ethanol containing few drops of piperidine, produced the unexpected cyanopyrimidine derivative 4 as a sole product and not 5 or 6 . The spectral data of 4 were in accordance with the proposed structure, where the IR showed the presence of two peaks at 3337 and $2213 \mathrm{~cm}-1$ corresponding to $\mathrm{OH}$ and $\mathrm{CN}$ groups respectively. Also, 1HNMR showed two at $\square 3.82$ (s, 1H, benzylic-H) and 10.43 (s, 1H, OH, D2O exchangeable).

While the reaction of $1 \mathrm{a}$ with 2-(4-chlorobenzylidene)malononitrile (7) furnished the enaminonitrile derivative 8 (Scheme 1).

The structure of 8 was supported by its IR spectrum which displayed characteristic peaks at 3339, 3235 and $2211 \mathrm{~cm}-1$ for $\mathrm{NH} 2$ and $\mathrm{CN}$, respectively. Also, 1HNMR displayed a signal at $\square 9.14$ (s, 2H, NH2, D2O exchangeable). 


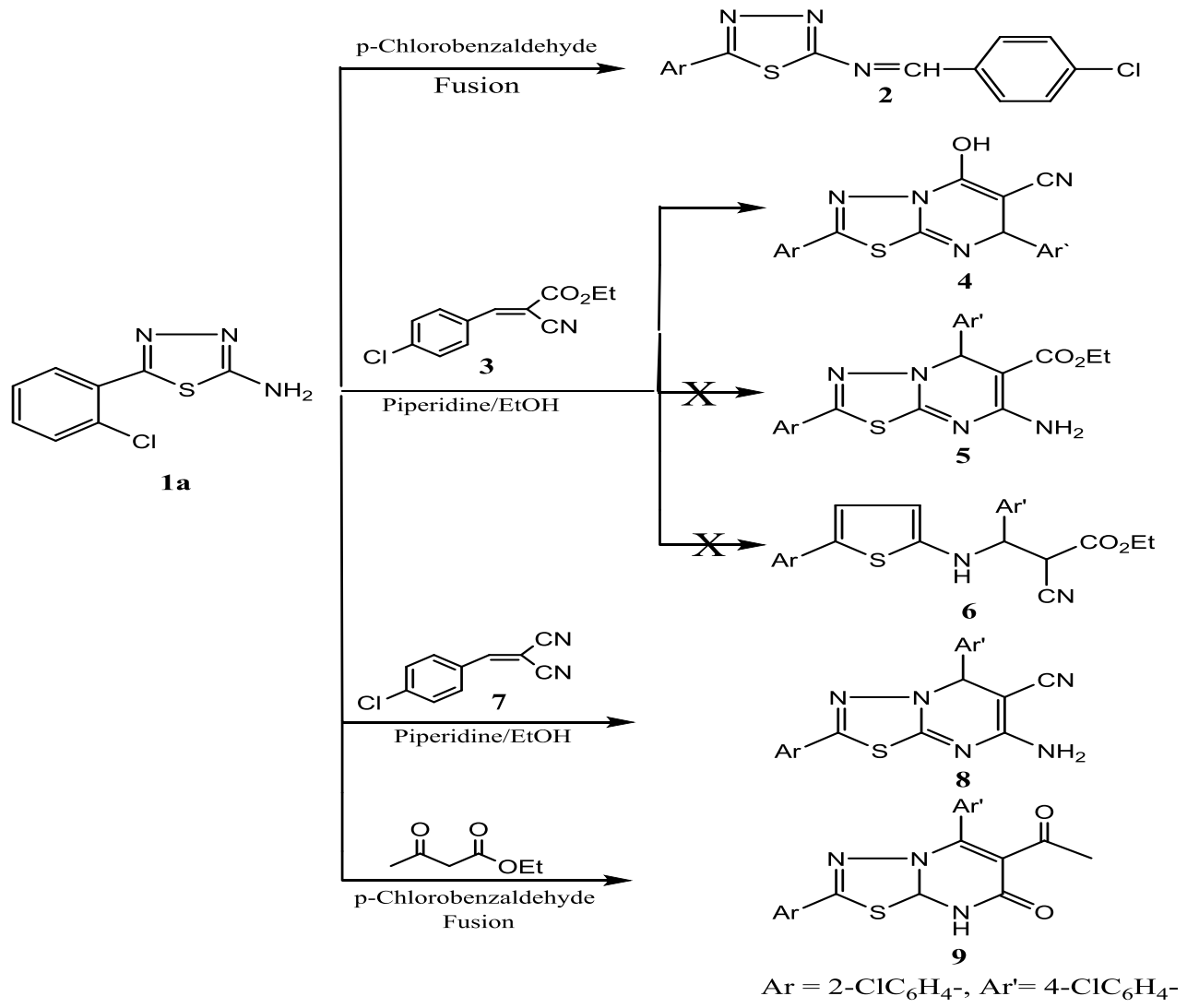

Scheme (1): Methods of synthesis of compounds 1-(4-Chlorophenyl)-N-(5(2-chlorophenyl)-1, 3, 4-thiadiazol-2-yl)-methan-imine (2), 2-(2Chlorophenyl)-5-(4-chlorophenyl)-7-hydroxy-5H-[1, 4]thiadiazolo-[3,2-a]pyrimidine-6-carbonitrile (4), 7-Amino-2(2-chlorophenyl)-5-(4-chlorophenyl)-5H-[1, 3, 4]thiadiazolo[3,2-a]pyrimidine-6-carbonitrile (8)

\& 6-Acetyl-2-(2-chlorophenyl)-5-(4-chlorophenyl)-8,8adihydro-7H-[1, 3, 4]-thiadiazolo[3,2-a]pyrimidin-7-one (9)

A speculated mechanism for the formation of compound 4 is shown in the scheme 2 . 


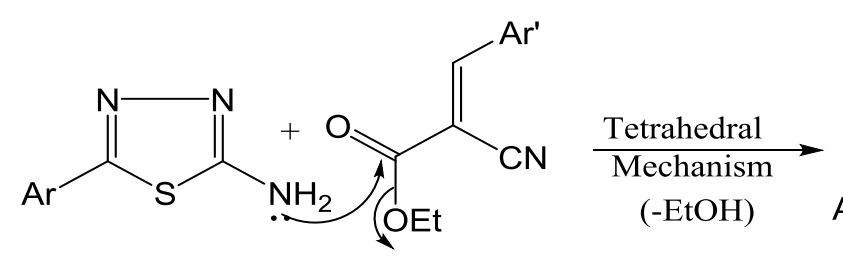<smiles>N#CC1=C(O)N=C2SC(Br)=NN2C1Br</smiles><smiles>N#C/C(=C/Br)C(=O)Nc1nnc(Br)s1</smiles>

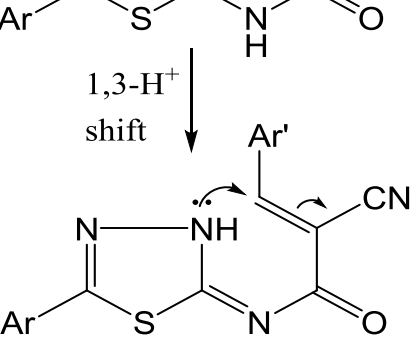

4

Scheme(2): Mechanism of formation of compound 2-(2-Chlorophenyl)-5-(4chlorophenyl)-7-hydroxy-5H-[1, 3, 4] thiadiazolo-[3,2a]pyrimidine-6-carbonitrile (4)

On the other hand, when compound $1 \mathrm{a}$ was fused at $60 \mathrm{oC}$ for $5 \mathrm{~h}$ with $\mathrm{p}$ chlorobenzaldehyde and ethyl acetoacetate, 6-acetylpyrimidinone derivative 9 was obtained. The proposed structure was in accordance with the spectral data, where the IR showed the following peaks: $3159 \mathrm{~cm}-1(\mathrm{NH}), 1698$ and $1649 \mathrm{~cm}-1(2 \mathrm{C}=\mathrm{O})$. Also, the $1 \mathrm{HNMR}$ spectrum displayed two peaks at 2.23 (s, 3H, COCH3) and 12.67 (s, 1H, NH, D2O exchangeable).

Compound 1a was also subjected to the reaction with different active methylene compounds under different conditions. Thus, when 1a was refluxed with ethyl cyanoacetate in the presence of sodium methoxide as a base, aminopyrimidinone derivative 10 was produced in $58 \%$ yield. While, when the same reaction was carried out under fusion conditions, it furnished the cyanoimidazolone derivative 12 (Scheme 3 ). 
The structure of 10 was elucidated from its spectral data where the IR spectrum exhibited peaks at 3287, 3102 and $1693 \mathrm{~cm}-1$ corresponding to $\mathrm{NH} 2$ and $\mathrm{C}=\mathrm{O}$ groups, respectively. Also, the MS spectrum showed a molecular ion peak at 278. The IR of 12 showed peaks at 2261 (CN) and $1701(\mathrm{C}=\mathrm{O})$, the MS spectrum exhibited molecular ion peak at 276.

Compound 12 was formed through the intermediate 11 (not isolated) which was produced from the elimination of ethanol molecule, followed by ring closure through elimination of hydrogen molecule.

Reaction of 1a with diethylmalonate under either fusion condition or refluxing in acetic acid produced the pyrimidindione derivative 13 . The structure was approved by the presence of two peaks at 1701 and $1683 \mathrm{~cm}-1$ corresponding to two carbonyl groups. Also, 1HNR showed a peak at d 2.21 (s, 2H, CO-CH2-CO), and molecular ion peak at 279.

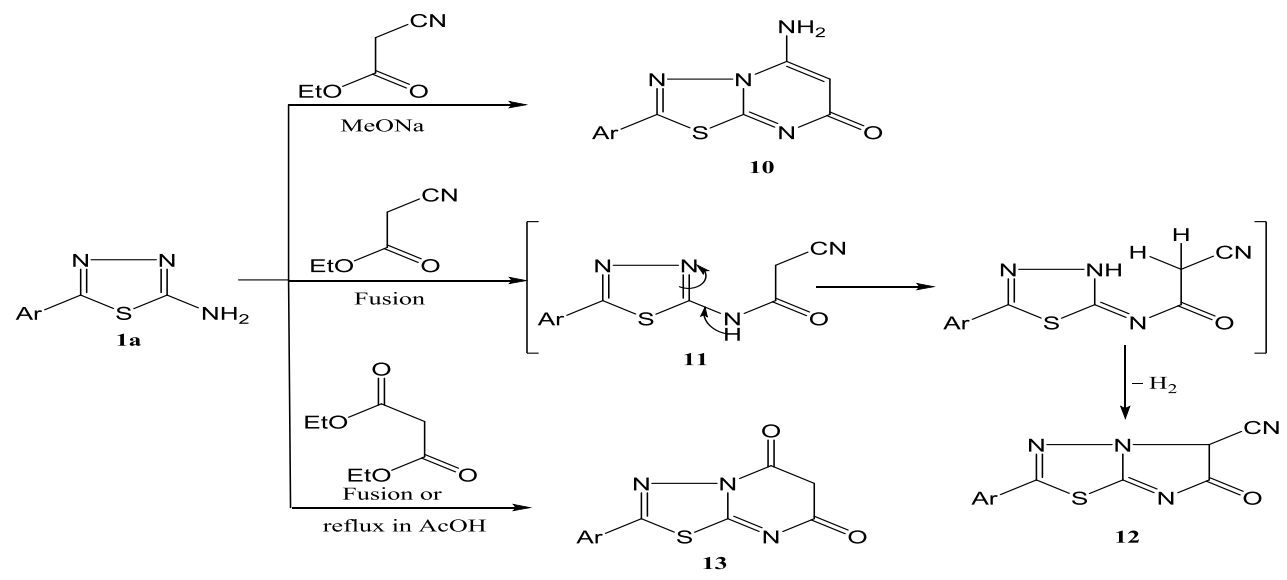

Scheme (3): Methods of synthesis of compounds 5-Amino-2-(2chlorophenyl)-7H-[1, 3, 4]thiadiazolo[3,2-a]pyrimidin-7-one (10) , 2-(2-Chlorophenyl)-6-oxo-5,6 dihydroimidazo[2,1-b][1, 3, 4]thiadiazole-5-carbonitrile (12). \& 2-(2-Chlorophenyl)-5H-[1, $3,4]$ thiadiazolo[3,2-a]pyrimidine-5,7(6H)-dione (13). 
The study was extended to investigate the reactivity of 1a towards some reagents containing sulfur. Thus, the reaction of 1a with phenyl isothiocyante in refluxing dioxane produced 1,3,4-thiadiazolo-1,2,4-thiadiazol-6-imine derivative 15 which was formed through the cyclization of the open chain intermediate 14.

The structure of 15 was confirmed by the presence of two peaks at 3329 and $3252 \mathrm{~cm}-1(\mathrm{NH})$ in its IR spectrum, and 1HNMR showed two peaks at 3.56 (s, 1H, N-CH-N) and 10.52 (s, 1H, NH, D2O exchangeable).

Thiomethylation of compound 1a took place by the reaction with sodium hydroxide and carbon disulfide followed by the addition of methyl iodide to afford dimethyl (5-(2-chlorophenyl)-1,3,4-thiadiazol-2-yl)carbon-

imidodithioate (16). The structure was supported by the IR spectrum which devoid any bands for the NH2 group, while 1HNMR spectrum showed a peak at $\square 4.24$ (s, $6 \mathrm{H})$ corresponding to two methyl groups. Also, the mass spectrum showed a molecular ion peak at 315 which is in accordance with the proposed structure.

The reaction of 1a with benzenesulphonyl chloride produced the expected product $\mathrm{N}$-(5-(2-chlorophenyl)-1,3,4-thiadiazol-2-yl)-benzenesulfonamide (17) through the elimination of $\mathrm{HCl}$ molecule (Scheme 4). The spectral data of 17 showed a peak at $3286 \mathrm{~cm}-1$ in the IR spectrum corresponding to NH group and 1HNMR spectrum exhibited a peak at $\square 7.42$ (s, 1H, NH, D2O exchangeable). 


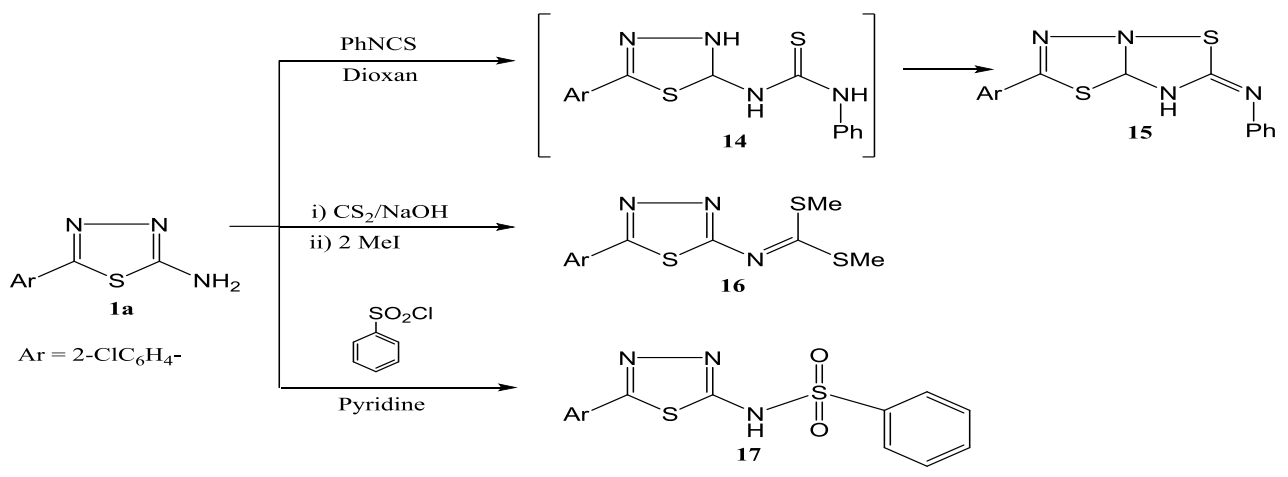

Scheme(4): Methods of synthesis of compounds 2-(2-Chlorophenyl)-Nphenyl-7,7a-dihydro-6H-[1, 3, 4]thiadiazolo[3,2-b]$[1,2,4]$ thiadiazol-6-imine (15), Dimethyl (5-(2-chlorophenyl)-1, 3, 4-thiadiazol-2-yl)carbonimidodithioate (16) \& N-(5-(2Chlorophenyl)-1, 3, 4-thiadiazol-2-yl)benzenesulfonamide (17)

Also, compound 1a underwent acetylation reaction using acetic anhydride to produce $\mathrm{N}$-acetylthiadiazole derivative 18 , where its structure

was approved by the IR spectrum which showed two peaks at 3161 and $1699 \mathrm{~cm}-1$ corresponding to $\mathrm{NH}$ and $\mathrm{C}=\mathrm{O}$ groups, respectively. Its $1 \mathrm{H}-\mathrm{NMR}$ spectrum displayed signals at d $2.23(\mathrm{~s}, 3 \mathrm{H}, \mathrm{COCH} 3)$ and $12.67(\mathrm{~s}, 1 \mathrm{H}, \mathrm{NH}$, D2O exchangeable), beside a molecular ion peak at 253 in its MS spectrum.

Reaction of 1a with diethyl acetylenedicarboxylate (DADC) in refluxing methanol afforded ethyl [1,3,4] thiadiazolo [3,2-a] pyrimidine-7-carboxylate derivative 20 . The reaction proceeded via a tetrahedral mechanism giving the intermediate 19, which underwent cyclization to produce the 20 . The structure was established depending on the spectral data, where the IR exhibited two peaks at 1744 and $1640 \mathrm{~cm}-1$ for the two carbonyl groups, the 1HNMR showed two peaks for the ethyl ester group at $\square 1.35$ (t, 3H, CH2- 
$\mathrm{CH} 3)$ and $4.43(\mathrm{q}, 2 \mathrm{H}, \mathrm{CH} 2-\mathrm{CH} 3)$ and the MS displayed a base molecular ion peak at 335 .

Finally, compound $1 \mathrm{~b}$ was reacted with chloroacetyl chloride in the presence of pyridine to furnish the chloroacetamide derivative 21 via tetrahedral mechanism followed by elimination of $\mathrm{HCl}$ molecule (Scheme 5).

Compound 21 exhibited a keto-enol tautomerism where the enol form is stabilized by the hydrogen bond with the $\mathrm{N}$-atom of the ring. this was supported by the presence of two peaks in the 1HNMR spectrum at $\square 12.65$ $(\mathrm{OH})$ and $13.06(\mathrm{NH})$. Also, the IR spectrum showed peaks at 3431, 3159 and $1701 \mathrm{~cm}-1$ corresponding to $\mathrm{NH}$ and $\mathrm{C}=\mathrm{O}$, respectively, beside the MS which showed a molecular ion peak at 379 .

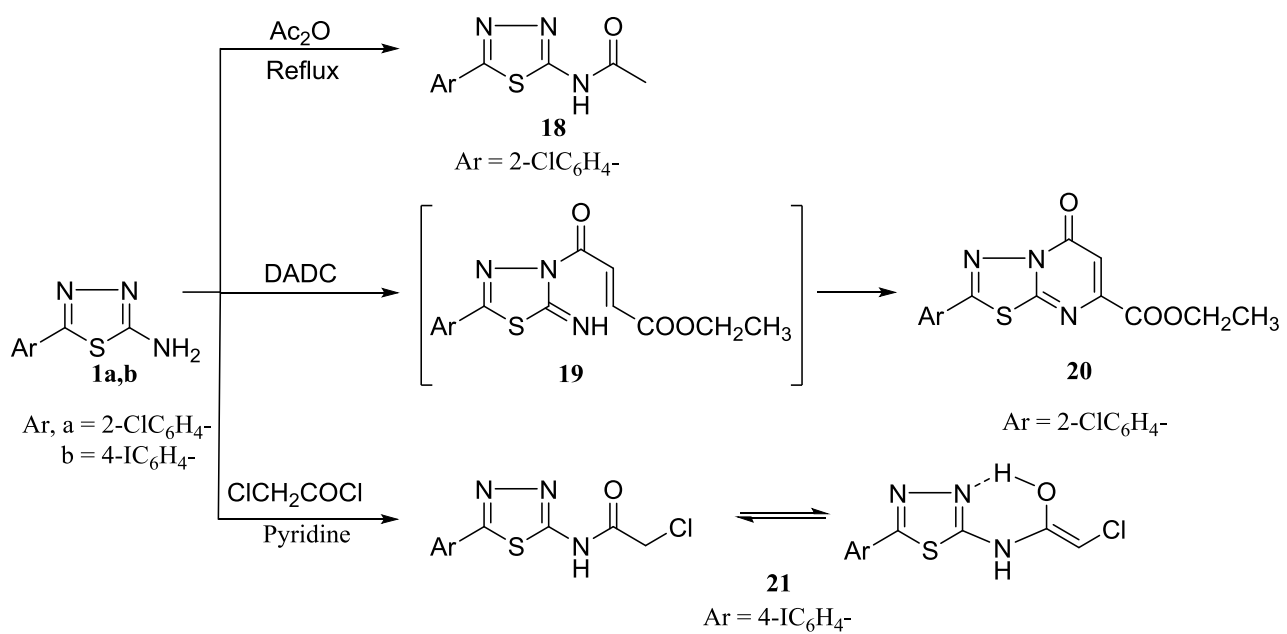

Scheme(5): Methods of synthesis of compounds N-(5-(2-Chlorophenyl)-1, 3, 4-thiadiazol-2-yl)acetamide (18) , Ethyl 2-(2-chlorophenyl)-5oxo-5H-[1, 3, 4] thiadiazolo[3,2-a]pyrimidine-7-carboxylate (20) \& 2-Chloro-N-(5-(4-iodophenyl)-1, 3, 4-thiadiazol-2yl)acetamide (21) 
2- Insecticidal activity: The data listed in Table (1) and illustrated by Fig (1) represent the insecticidal activity of the synthesized thiadiazolopyrimidine derivatives. From the data we could conclude that, as the treatment concentration of the tested compounds increases, the mortality percentage increases, as well as, its insecticidal activity increases. Compound 8 was the most potent compound where it recorded the lowest LC50 value of $114.99 \mathrm{ppm}$ and the slope of its line was 1.632 .

On the other hand compound 20 recorded the least insecticidal activity against the tested larvae of spodoptera littoralis where its LC50 was the lowest value to be $605.39 \mathrm{ppm}$ with slope equal to 1.046 . The other tested pyrimidine derivatives could be arranged as follow 4, 13 and 10 according to their LC50, where their values were 115.04. 176.96 and 361.45 ppm respectively.

Table(1): The insecticidal activity of newly synthesize thiadiazolopyrimidine derivatives.

\begin{tabular}{|c|c|c|c|c|c|c|c|c|c|}
\hline \multirow{2}{*}{ Compd. } & \multicolumn{5}{|c|}{ Concentrations in ppm } & \multirow{2}{*}{ LC50 } & \multirow{2}{*}{ LC90 } & \multirow{2}{*}{$\begin{array}{r}\text { Toxicity } \\
\text { Index }\end{array}$} & \multirow{2}{*}{ Slope } \\
\hline & 250 & 500 & 750 & 1000 & 1250 & & & & \\
\hline 4 & $\overline{667.66}$ & 80.72 & 86.58 & $\overline{89.91}$ & $\overline{92.05}$ & 115.04 & 1007.99 & 99.96 & 1.632 \\
\hline 8 & 69.55 & 83.35 & 89.16 & 92.28 & 94.19 & 114.99 & 801.66 & 100.00 & 1.517 \\
\hline 13 & 54.82 & 64.23 & 69.39 & 72.84 & 75.37 & 176.96 & 6811.13 & 64.98 & 0.808 \\
\hline 10 & 43.98 & 55.29 & 61.78 & 66.20 & 69.48 & 361.45 & 8194.91 & 31.81 & 0.946 \\
\hline 20 & 34.39 & 46.54 & 53.88 & 59.02 & 62.91 & 605.39 & 10163.41 & 18.99 & 1.046 \\
\hline
\end{tabular}

The insecticidal activity of the synthesized tested pyrimidine derivatives also could be expressed as the value of the toxicity index to be as follow 8,4 , 13,10 and 20 where their toxicity indexes were 100, 99.96, 64.98, 31.81 and 18.99 respectively as calculated using LC50 of the most potent compound. 
J. Environ. Sci.

Institute of Environmental Studies and Research - Ain Shams University

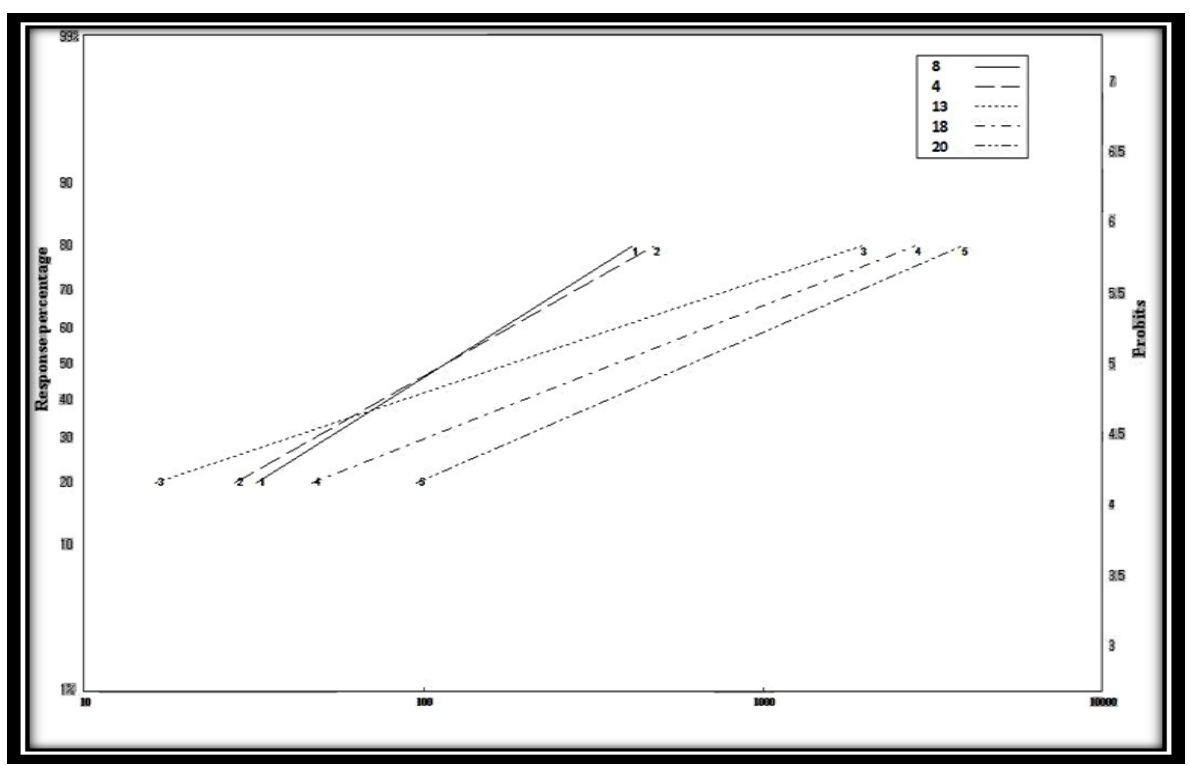

Fig(1): The Ldp line of the synthesized thiadiazolopyrimidine derivatives.

The previous potency of the synthesized tested compounds may be explained in terms of structure elucidations of the synthesized thiadiazolopyrimidine derivatives, where the presence of electron with drawing group such as carbonyl group $(\mathrm{C}=\mathrm{O})$ or the in benzene ring as chlorine atom $(\mathrm{Cl})$ results in increasing its insecticidal activity as in compounds 8 and 4 . 
Table(2): The insecticidal activity of newly synthesized thiadiazole derivatives.

\begin{tabular}{|c|c|c|c|c|c|c|c|c|c|}
\hline \multirow{2}{*}{ Compd } & \multicolumn{5}{|c|}{ Concentration in ppm } & \multirow{2}{*}{ LC50 } & \multirow{2}{*}{ LC90 } & $\begin{array}{c}\text { Toxicity } \\
\text { Index }\end{array}$ & \multirow{2}{*}{ slope } \\
\cline { 2 - 10 } & $\mathbf{2 5 0}$ & $\mathbf{5 0 0}$ & $\mathbf{7 5 0}$ & $\mathbf{1 0 0 0}$ & $\mathbf{1 2 5 0}$ & & & \\
\hline \hline 2 & 26.40 & 42.50 & 52.77 & 59.98 & 65.36 & 672.66 & 5019.35 & 52.98 & 1.468 \\
\hline 15 & 27.62 & 44.48 & 54.94 & 62.25 & 67.65 & 620.26 & 4405.49 & 57.46 & 1.505 \\
\hline 9 & 58.02 & 61.45 & 73.89 & 81.24 & 85.97 & 356.38 & 1582.25 & 100 & 1.979 \\
\hline 17 & 26.38 & 44.04 & 55.24 & 62.49 & 68.67 & 620.44 & 3924.37 & 57.44 & 1.599 \\
\hline 16 & 29.69 & 42.63 & 50.69 & 56.41 & 66.77 & 724.47 & 9345.07 & 49.19 & 1.154 \\
\hline $\mathbf{1 a}$ & 26.68 & 38.75 & 46.45 & 52.01 & 53.31 & 901.28 & 12633.88 & 39.54 & 1.118 \\
\hline $\mathbf{2 1}$ & 26.30 & 46.64 & 59.38 & 67.91 & 73.96 & 556.10 & 2799.59 & 64.09 & 1.826 \\
\hline $\mathbf{1 2}$ & 38.44 & 55.48 & 65.18 & 71.54 & 76.06 & 400.73 & 3138.80 & 88.93 & 1.434 \\
\hline $\mathbf{1 8}$ & 24.54 & 41.31 & 52.19 & 59.86 & 65.57 & 691.53 & 4590.47 & 51.54 & 1.599 \\
\hline
\end{tabular}

The data listed in Table (2) and illustrated by Fig. (2) and (3) revealed the insecticidal activity of the synthesized thiadiazole derivatives expressed as mortality percentages, LC50, LC90 and toxicity indexes.

The data concluded that, the mortality percentage of the tested thiadiazole derivatives is directly proportional with the concentration of the tested compounds.

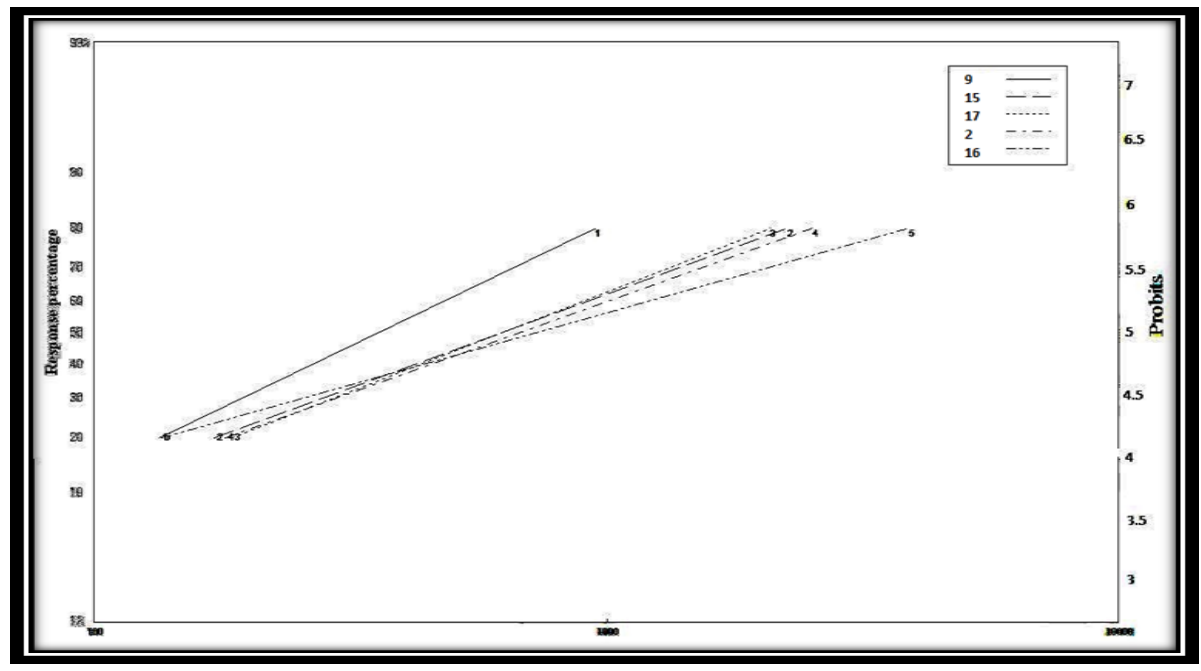

Fig(2): the Ldp line of the thiadiazole derivatives. 


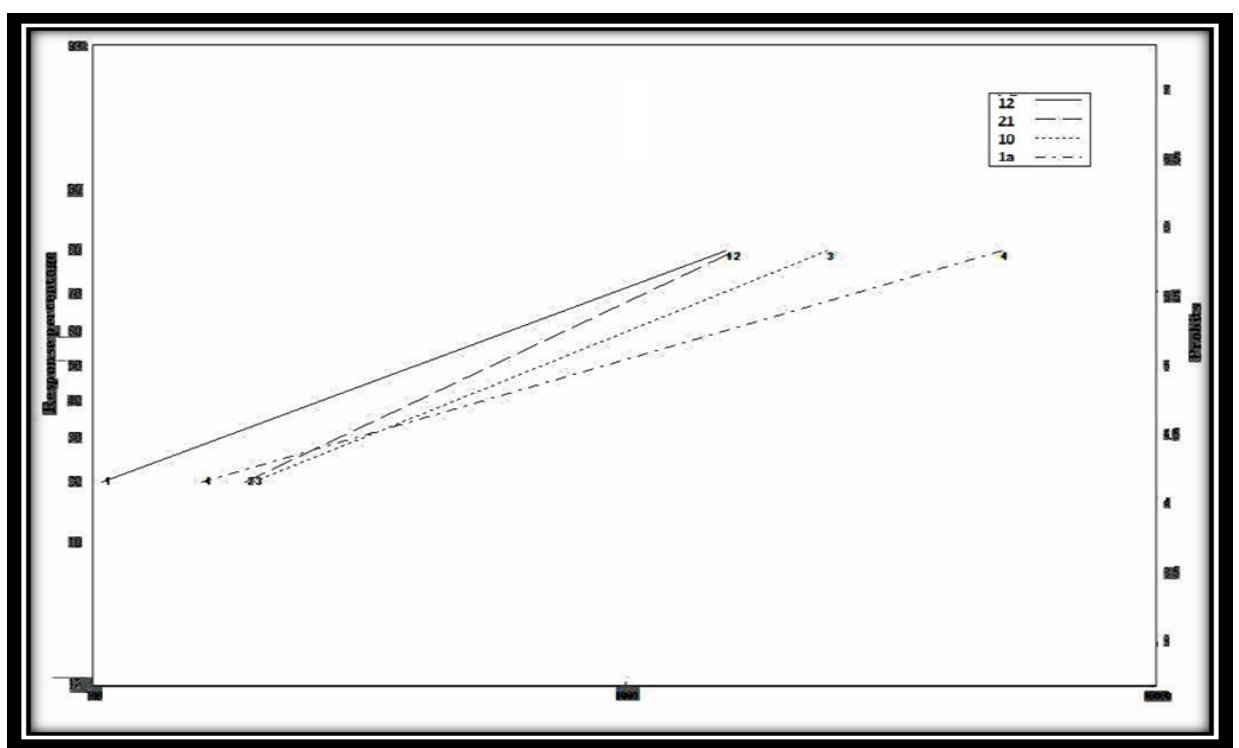

Fig(3): the Ldp line of the thiadiazole derivatives.

The intensive study of these data reveal that, compound 9 was the most potent thiadiazole derivative among the tested compounds, where this compound recorded LC50 value of 356.38 ppm and its line's slope was 1.979.

On contrast, the least bioactivity was found with thiadiazole derivative 1a which is the starting material for all of the tested compounds. 1a recorded LC50 of $901.28 \mathrm{ppm}$ and its lethal dose propit line's slope was 1.118. The other tested synthesized derivatives could be arranged as follow according to their LC50 values 12, 21, 15, 17, 2, 18 and 16 where the LC50 values of these compounds where 400.73, 556.10, 620.26, 620.44, 672.66, 691.53 and 724.47 respectively.

From the other point of view we could study the insecticidal properties of the tested thiadiazole derivatives by taking the toxicity indexes in consideration. The arrangement of the compounds according to their toxicity 
indexes were $9,12,21,15,17,2,18,16$ and 1 a with the values $100,88.93$, $64.09,57.46,57.44,52.98,51.54,49.19$ and 39.54 on sequence.

The previous arrangement of the tested thiadiazole may be declared by studying the structure of the synthesized compounds where, the presence of electron withdrawing group as carbonyl group $(\mathrm{C}=\mathrm{O})$ and chlorine atom $(\mathrm{Cl})$ in p-position of benzene ring attached to the thiadiazole ring facilitate the erosion of the thiadiazole moiety to interfere with the RNA in the processes of protein synthesis. Also as their number in the molecule increase the compound bioactivity also increase, again, as the electronegativity of the substituents group increases, the bioactivity of the synthesized product also increases.

Generally, the insecticidal potency of the thiadiazolopyrimidine derivatives were more than the other thiadiazole derivatives. This may be explained in terms of the presence of pyrimidine moiety and the effect of the substituents present on it.

The synthesized compounds could be used in the field of pest control using them in proper pesticide formulations.

\section{CONCOLUSION}

Many thiadiazole derivatives were prepared from commercially available materials. The newly synthesized compounds were tested against 4th instar larvae of S. Littoralis, most of the tested compounds showed good activity. Thus, the synthesized compounds could be used in the field of pest control using them in proper pesticide formulations. 
J. Environ. Sci.

Institute of Environmental Studies and Research - Ain Shams University

\section{REFERENCES}

Abbot, W. S. (1925). A method of computing the effectiveness of insecticides. J. Econ. Entomol., 18, 265-267.

Ahmed, M. (2009). Observed potentiation between pyrethroid and organophosphorus insecticides for the management of Spodoptera litura (Lepidoptera: Noctuidae). Crop Protection, 28, 264-268.

Azab, M.E.; Rizk, S.A, Amr, A.E. (2015). Synthesis of Some Novel Heterocyclic and Schiff Base Derivatives as Antimicrobial Agents. Molecules, 20, 18201-18218.

Azab, M. E.; Rizk, S. A.; Mahmoud N. F. (2016). Facile synthesis, characterization and antimicrobial evaluation of novel heterocycles, Schiff bases and N-nucleosides bearing phthalazine moiety. Chem. Pharm. Bull., 64 (5), 349-350.

Chen, C.; Zhang, Z., Du, M.; Wang, S. and Wang, Y. (2007). Synthesis of N[[(5-mercapto-1,3,4-thiadiazol-2-yl)amino]carbonyl]benzamide and 2-(phenoxy)-N-[[(5-mercapto-1,3,4-thiadiazol-2-yl)amino]carbonyl]acetamide derivatives and determination of their activity as plant growth regulators. Chin. J. Org. Chem. 27,1444-1447.

Finney, M. D. J.; (1952). Probit Analysis, 3rd Edn. Cambridge Univ. Press, London, pp: 333.

Flefel, E.M.; El-Sayed A.W.; Mohamed, A.M.; El-Sofany, W.I.; Awad, H.M.; (2017). Synthesis and Anticancer Activity of New 1-Thia-4azaspiro-[4.5]decane, Their Derived Thiazolopyrimidine and 1,3,4-Thiadiazole Thioglycosides. Molecules, 22, 170.

Kalhora, M. and Dadrasb, A. (2013). Synthesis, characterization, and herbicidal activities of new 1,3,4-oxadiazoles, 1,3,4-thiadiazoles, and 1,2,4-triazoles derivatives bearing (R)-5-chloro-3-fluoro-2phenoxypyridine. J. Heterocycl. Chem., 50, 220-224.

Li, F.; MO, Q.; Duan W.; Lin, G.; Cen, B.; Chen., N.; Yang Z. (2014). Synthesis and insecticidal activities of N-(5-dehydroabietyl-1,3,4thiadiazol-2-yl)-benzenesulfonamides. Med. Chem. Res., 23, $4420-4426$. 
Maddila, S.; Gorle, S.; Sampath, Ch.; Lavanya, P. (2016). Synthesis and antiinflammatory activity of some new 1,3,4-thiadiazoles containing pyrazole and pyrrole nucleus. J. Saudi Chem. Soc., 20, S306S312.

Madkour, H. M. F.; Irshad, A.; Farina, Y.; Al-Kahraman, Y. M. S. A.;Baloch, N. (2014). Evaluation of Some Thiosemicarbazones as Potential Antileishmanial Agents. Int. J. Sci. \& Eng. Res., 5(2), 198- 204

Madkour, H. M. F.; Kandeel, K. A.; Salem, M. S.; Haroun, S. M. (2014).Antioxidant Activity of Novel Pyrimidines Derived from Arylidenes. Intern. J. Pharm. Sci \& and Health Care, 4(2), 102115

MO, Q.J.; Liu, L.Z.; Duan W.G.; Cen, B.; Lin, G. S.; Chen., N.Y.; Huang, Y.; Liu, B.M. (2015). Synthesis and insecticidal activities of $\mathrm{N}-(5-$ dehydroabietyl-1,3,4-thiadiazol-2-yl)-N'-substituted thioureas. Chem. \& Indust. of Forest Products, 35(2), 8-16.

Mullick, P; Khan, S. A.; Verma, S.; Alam, O. (2011). Thiadiazole derivatives as potential anticonvulsant Agents. Bull. Korean Chem. Soc., 32(2), 1011-1016.

Patel, H. M.; Noolvi, M. N.; Sethi, N. S.; Gadad, A. K.; Cameotra, S. S. (2017). Synthesis and antitubercular evaluation of imidazo[2,1b][1,3,4]-thiadiazole derivatives. Arab. J. Chem. 10, S996-S1002

Qian, Q.; Zhu, Y.; Zhang, M.; Lu, D.; Cao, W.; Song, L.; Huang, Q. (2013). Efficient synthesis and insecticidal activity of novel pyridin-3-yl$[1,2,4]$ triazolo[3,4-b][1,3,4]thiadiazoles. Monatsh. Chem. 144, 231-236.

Rahman, M. A.; Shakya, A. K.; Wahab S.; Ansari; N. H. (2014). Synthesis of some new thiadiazole derivatives and their anticonvulsant activity. Bulg. Chem. Commun., 46(4), 750 - 756.

Rezki, N.; Al-Yahyawi , A. M.; Bardaweel, S. K.; Al-Blewi, F. F. ; Aouad, M. R. (2015). Synthesis of Novel 2,5-Disubstituted-1,3,4thiadiazoles Clubbed 1,2,4-Triazole, 1,3,4-Thiadiazole, 1,3,4Oxadiazole and/or Schiff Base as Potential Antimicrobial and Antiproliferative Agents. Molecules, 20, 16048-16067. 
Yu, L.; Gan, X., Zhou, D.; He, F.; Zeng, S.and Hu, D. (2017). Synthesis and antiviral activity of novel 1,4-pentadien-3-one derivatives containing a 1,3,4-thiadiazole moiety. Molecules, 22, 658.

Zhang, L.J; Yang, M.Y; Sun, Z.H; Tan, C. X.; Weng, J.Q.; Wu, H. K.; Liu, X. H. (2014). Synthesis and Antifungal Activity of 1,3,4Thiadiazole Derivatives Containing Pyridine Group. Letters in Drug Design \& Discovery, 11(9),1107-1111.

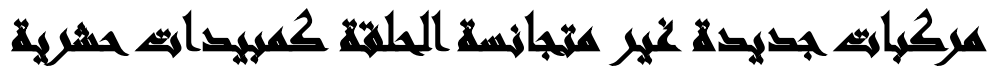

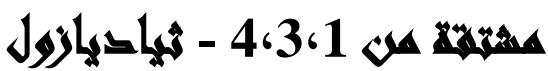

[r]

حسن فوزى مدكور (')- محمد عماد عزب(') - على فهمى على(؟) - محمد صبحى على (')

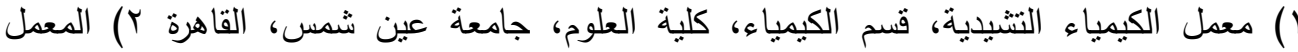

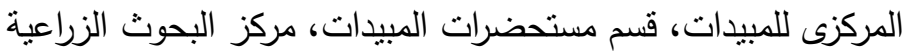

\section{المسريطتص}

تعتبر نباتات المحاصيل المصدر الرئيسى للغذاء الآدمى ولكن تحدث خسائر سنوية اقتصادية ضخمة بسبب الحشرات والافات التى تصيب هذه النباتات. ولقد تتامى اهتمام الباحثين في هذات البات البحث

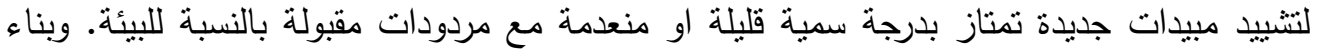

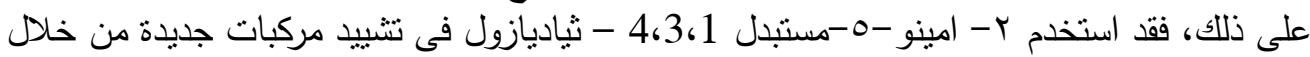

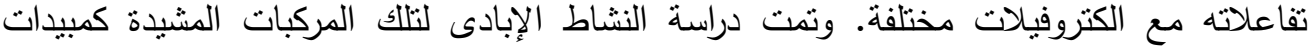

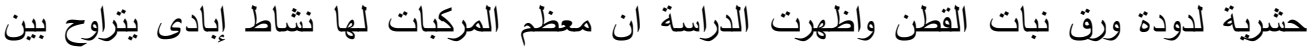

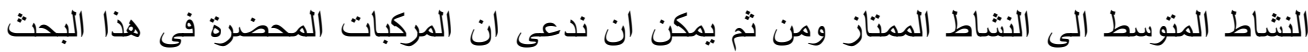

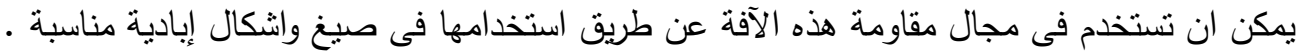
الكلمات الدالة: النشاط الإبادى للحشرات، سبودوبترليتروراليس. 